\title{
Griepvaccinatie en sterfte op lange termijn
}

Citation for published version (APA):

Verhees, R., Thijs, C., Ambergen, A., Dinant, G., \& Knottnerus, A. (2020). Griepvaccinatie en sterfte op lange termijn: Follow-up 25 jaar na een RCT bij ouderen. Huisarts en Wetenschap, 63, 16-19.

https://doi.org/10.1007/s12445-020-0416-0

Document status and date:

Published: 01/01/2020

DOI:

10.1007/s12445-020-0416-0

Document Version:

Publisher's PDF, also known as Version of record

Document license:

Taverne

Please check the document version of this publication:

- A submitted manuscript is the version of the article upon submission and before peer-review. There can be important differences between the submitted version and the official published version of record.

People interested in the research are advised to contact the author for the final version of the publication, or visit the DOI to the publisher's website.

- The final author version and the galley proof are versions of the publication after peer review.

- The final published version features the final layout of the paper including the volume, issue and page numbers.

Link to publication

\footnotetext{
General rights rights.

- You may freely distribute the URL identifying the publication in the public portal. please follow below link for the End User Agreement:

www.umlib.nl/taverne-license

Take down policy

If you believe that this document breaches copyright please contact us at:

repository@maastrichtuniversity.nl

providing details and we will investigate your claim.
}

Copyright and moral rights for the publications made accessible in the public portal are retained by the authors and/or other copyright owners and it is a condition of accessing publications that users recognise and abide by the legal requirements associated with these

- Users may download and print one copy of any publication from the public portal for the purpose of private study or research.

- You may not further distribute the material or use it for any profit-making activity or commercial gain

If the publication is distributed under the terms of Article $25 \mathrm{fa}$ of the Dutch Copyright Act, indicated by the "Taverne" license above, 


\title{
Griepvaccinatie en sterfte op lange termijn
}

\section{Follow-up 25 jaar na een RCT bij ouderen}

\author{
Ruud Verhees, Carel Thijs, Ton Ambergen, Geert-Jan Dinant, André Knottnerus
}

Vanuit de hypothese dat griepvaccinatie residuele bescherming biedt tegen griepstammen die later kunnen circuleren, evalueerden we na 25 jaar de langetermijneffecten van een eenmalige griepvaccinatie. Daarvoor gebruikten we de gegevens van een gerandomiseerde placebogecontroleerde trial. Deze trial toonde aan dat griepvaccinatie griep kan voorkomen. Verder gebruikten we de follow-upgegevens van onder andere CBS en Gemeentelijke Basisadministratie om de totale sterfte en de sterfte aan cardiovasculaire of respiratoire oorzaken onder de trialdeelnemers na 25 jaar te berekenen. Met behulp van regressieanalyses bepaalden we de invloed van leeftijd en comorbiditeit op de langetermijnsterfte. Van $\mathbf{9 8 \%}$ van de deelnemers konden we de vitale status op 1 januari 2017 achterhalen. In de groep als geheel was er geen aantoonbaar verschil in langetermijnsterfte tussen de interventiegroep (vaccinatie) en de controlegroep (placebo). Wel is er een mogelijk klinisch relevant effect op langetermijnsterfte bij jongere ouderen.

Griepvaccinatie beschermt ouderen tegen griep, maar een effect op sterfte is nooit direct aangetoond op basis van gerandomiseerd gecontroleerd onderzoek. ${ }^{1}$ Er is wel observationeel onderzoek dat suggereert dat griepvaccinatie de sterfte onder ouderen met circa 30\% kan reduceren, maar in zulk onderzoek kunnen selectiebias en confounding een rol spelen. ${ }^{2}$ Critici dringen daarom aan op een voldoende krachtig placebogecontroleerd onderzoek. ${ }^{3} \mathrm{Er}$ zijn echter ethische en methodologische bezwaren tegen een dergelijk onderzoek. ${ }^{4}$

Onderzoek doet vermoeden dat vaccinatie griepgerelateerde complicaties kan voorkomen of verminderen en residuele bescherming biedt tegen griepstammen die later kunnen circuleren. ${ }^{5-8}$ Daardoor zou griepvaccinatie een effect op sterfte kunnen hebben dat langer duurt dan één griepseizoen. In dit onderzoek evalueren we de langetermijnsterfte onder ouderen die in het seizoen 1991/1992 een eenmalige influenzavaccinatie ontvingen in het kader van een grote influenzatrial. Veel van de betrokken ouderen waren niet eerder ingeënt tegen influenza, aangezien het leeftijdscriterium voor influenzavaccinatie pas in 1996 werd ingevoerd.

Dit onderzoek verscheen eerder als: Verhees RA, Thijs C, Ambergen T, Dinant GJ, Knottnerus JA. Influenza vaccination in the elderly: 25 years follow-up of a randomized controlled trial. No impact on long-term mortality. PLoS ONE 2019;14[5]:e0216983. Publicatie gebeurt met toestemming.

\section{METHODE}

\section{Gegevensverzameling}

We voerden dit follow-uponderzoek uit 25 jaar na dato, onder de deelnemers aan een RCT die in het griepseizoen van 1991/1992 de effectiviteit van influenzavaccinatie onder ouderen evalueerde. Destijds includeerden vijftien Zuid-Nederlandse huisartsenpraktijken 1838 patiënten $\geq 60$ jaar van wie niet bekend was dat ze behoorden tot een hoogrisicogroep (490 deelnemers hadden een cardiovasculair, pulmonaal of metabool probleem, maar dat was in de ogen van de huisarts niet van dien aard dat zij binnen de risicogroepen voor vaccinatie vielen). $\mathrm{Na}$ randomisatie ontvingen de deelnemers een intramusculaire injectie met het geïnactiveerde quadrivalente griepvac$\operatorname{cin}(n=927)$ of met zoutoplossing $(n=911) .{ }^{1}$

Wij verrijkten de trialgegevens uit 1991 met sterftecijfers van het CBS, die beschikbaar waren tot 2017. Via een genealogisch onderzoek in de Gemeentelijke Basisadministratie (GBA), het Centraal Bureau voor de Genealogie (CBG), het Rijksarchief Limburg en de administratie van de betrokken huisartsen verzamelden we gegevens die relevant waren om de CBS-search te optimaliseren. Bij enkele deelnemers kwamen de gevonden persoonsgegevens niet overeen met de in de trial gerapporteerde patiëntkarakteristieken. In dit geval werden doorgaans de data van de genealogische search aangehouden.

\section{Eindpunten}

We definieerden zes eindpunten: overall mortaliteit (alle 
ICD-codes); sterfte door pneumonie of influenza (ICD-9-codes 480-487, ICD-10-codes J09-J18); respiratoire doodsoorzaken (ICD-9-codes 460-519, ICD-10-codes J00-J99); circulatoire doodsoorzaken (ICD-9-codes 390-459, ICD-10codes I00-I99); respiratoire of circulatoire doodsoorzaken; en sterfte primair, secundair dan wel tertiair door longziekten (respiratoir gerelateerde sterfte).

Onze gegevens voor de overall mortaliteit reikten tot januari 2017, die voor primaire doodsoorzaken tot 1 januari 2016 en die voor secundaire en tertiaire doodsoorzaken tot 1 januari 2013. Voor elk eindpunt werd ook de seizoensgebonden sterfte - gedefinieerd als sterfte die optrad tussen december en juni in beschouwing genomen.

We betrokken de volgende aanvangskenmerken als onafhankelijke covariabelen in de analyse: trialinterventie (vaccinatie of placebo), leeftijd, geslacht, medische voorgeschiedenis zoals bekend in 1991 (cardiovasculaire aandoening, pulmonale aandoening, diabetes mellitus), rookstatus en eerdere vaccinatiestatus (influenzavaccinatie in 1989/1990 en/of 1990/1991). Voor deze variabelen werd rekening gehouden met mogelijke modificatie van het effect van de trialvaccinatie.

\section{Statistische analyse}

Associaties tussen trialvaccinatie en overleving brachten we in kaart met Kaplan-Meier-overlevingscurven. We voerden univariate en multivariabele Cox proportional hazard-analyses uit om een inschatting te maken van de hazardratio (HR) van trialvaccinatie voor de totale sterfte, en het 95\%-betrouwbaarheidsinterval. De onafhankelijke covariabelen en hun mogelijke tweeweginteracties werden ook in het model opgenomen. Vervolgens voerden we een backward stepwise multivariabele Cox-regressieanalyse uit met $\mathrm{p}=0,05$ als drempelwaarde voor significantie.

We evalueerden de relatie tussen trialvaccinatie en seizoensgebonden of specifieke doodsoorzaken met behulp van competing risk-regressieanalyse. Hiervoor namen we de genoemde covariabelen, hun mogelijke interacties met trialvaccinatie en acht biologisch plausibele tweeweginteracties in het model op (zie onze originele publicatie). ${ }^{9}$ Vanwege het beperkte aantal events werden subgroepanalyses voor leeftijd en medische voorgeschiedenis alleen uitgevoerd op het eindpunt overall mortaliteit. Bij de subgroepanalyses werden alleen de covariabelen in het model opgenomen, zonder mogelijke interactietermen.

Van sommige onderzoeksdeelnemers ontbraken gegevens over roken $(n=82)$ en eerdere vaccinaties $(n=2)$. We maakten daarom in de analyse een aparte groep aan met 'rookstatus onbekend'; de twee deelnemers van wie eerdere vaccinatiegegevens ontbraken, excludeerden we.

Voor de Cox-regressieanalyses gebruikten we SPSS versie 23, de competing risk-analyses voerden we uit met het competing risk package in ' $\mathrm{R}$ ' versie 3.3.1.

Als de CBS-search geen informatie opleverde over de overlevingsstatus van een deelnemer $(n=52)$, gebruikten we alternatieve bronnen (zie originele publicatie) om de meest

\section{WAT IS BEKEND?}

- In 1991/1992 bleek uit een RCT in vijftien Zuid-Nederlandse huisartsenpraktijken dat griepvaccinatie effectief was in het voorkomen van griep.

- Onderzoek doet vermoeden dat griepvaccinatie residuele bescherming biedt tegen griepstammen die later kunnen circuleren.

\section{WAT IS NIEUW?}

- Een vervolgonderzoek met 25 jaar follow-up kan geen langetermijneffect aantonen van een [eenmalige] griepvaccinatie op de sterfte onder ouderen.

- Een klinisch relevante toename van de mediane overleving in de leeftijdsgroep 60-64 jaar door griepvaccinatie kan niet worden uitgesloten.

- Effectiviteitsonderzoek zou geschikt moeten worden gemaakt voor langdurige follow-up met aandacht voor deze leeftijdsgroep.

recente follow-updatum te verkrijgen en censureerden we de casus vanaf dat moment.

\section{Ethische overwegingen en privacy}

In 1991 is geen toestemming aan deelnemers gevraagd om in een later stadium overlijdensgegevens te mogen opvragen, aangezien dit buiten het doel van de originele trial viel. Maastricht Universitair Medisch Centrum beoordeelde ons vervolgonderzoek als niet WMO-plichtig. Het CBS heeft ingestemd met anonieme koppeling en verwerking van de gegevens.

\section{RESULTATEN}

\section{Follow-up}

Tijdens de follow-upduur van in totaal 29.867 persoonsjaren (mediaan 17,34 jaar) overleden 1418 van de 1838 deelnemers (77,1\%); 382 deelnemers (20,8\%) waren op 1 januari 2017 nog in leven; van 38 deelnemers $(2,1 \%)$ kon de status niet worden achterhaald. Van 1340 van de 1418 overledenen (94,5\%) was de doodsoorzaak bekend.

\section{Patiëntkenmerken}

[Online Tabel 1] toont de kenmerken van de deelnemers. Het bijwerken van patiëntkenmerken (zie Methode) resulteerde niet in relevante verschillen tussen de vaccin- en placebogroep.

\section{Langetermijninvloed van (eenmalige) griepvaccinatie op sterfte}

De mediane overleving in de interventiearm was 17,39 jaar (interkwartielafstand 10,61 tot 24,58) versus 17,20 jaar voor de controlearm (interkwartielafstand 10,02 tot 23,70), een verschil van 2,23 maanden (95\%-BI -14,68 tot 19,14). De [figuur en online tabel 2] tonen de Kaplan-Meier-overlevingscurves 


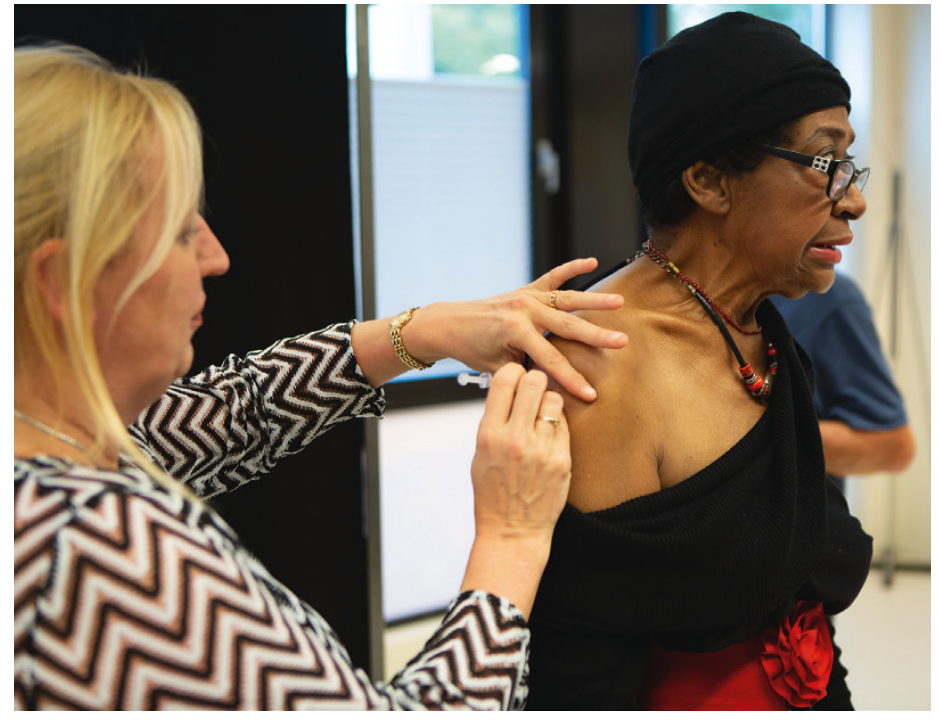

Een effect van griepvaccinatie op sterfte is nooit direct bewezen.

Foto: Margot Scheerder

voor verschillende leeftijdsgroepen en de overlevingstabel met hazardratio's. Wij vonden geen statistisch significant effect van (eenmalige) influenzavaccinatie op mortaliteit (gecorrigeerde HR 0,95; 95\%-BI 0,85 tot 1,05). Sensitiviteitsanalyses (niet gepresenteerd) toonden consistente resultaten.

De hazardratio's voor vaccin versus placebo op de verschillende eindpunten zijn weergegeven in [tabel 3]. Voor de groep als geheel kon op geen van de eindpunten een verschil in overleving worden aangetoond tussen vaccinatie en placebo. Ook de analyses van subgroepen met comorbiditeit, eerdere vaccinatie of hogere leeftijd toonden geen significant effect van vaccinatie op sterfte. (Voor seizoensgebonden sterfte en subgroepanalyses, zie tabel 3 en 4 in onze originele publicatie. $\left.{ }^{9}\right)$

Wel suggereren de resultaten (zie [figuur en tabel 2]) dat vaccinatie op de leeftijd van 60-64 jaar de hoogste sterftereductie geeft: de gecorrigeerde HR is 0,86 (95\%-BI 0,72 tot 1,03$)$. In de gevaccineerde groep bedroeg de mediane overleving 23,18 jaar versus 21,50 jaar in de placebogroep. Dit verschil van 20,11 maanden $(95 \%$-BI 2,35 tot 37,87$)$ was statistisch significant.

\section{BESCHOUWING}

We konden in een follow-up van 25 jaar geen verband aantonen tussen eenmalige griepvaccinatie en langetermijnsterfte bij ouderen - hetzij de totale sterfte of de sterfte door specifieke doodsoorzaken. Ook een langetermijneffect van vaccinatie op seizoensgebonden sterfte konden we niet aantonen. De puntschatting van de overleving was consistent in het voordeel van de vaccingroep gedurende de gehele follow-up, maar bleek statistisch niet significant.

Gezien de discussie over de invloed van leeftijd op de effectiviteit van vaccinatie, was een Cox-regressieanalyse per leeftijdsgroep relevant. Ook bij jongere ouderen (60-64 jaar) heeft influenza een substantieel aandeel in de sterfte en het aantal ziekenhuisopnamen..$^{10}$ De analyse binnen deze sub- groep suggereerde dat (eenmalige) vaccinatie een relevant langetermijneffect kan hebben op de mediane overleving van 20,11 maanden (95\%-BI 2,35 tot 37,87). De bovengrens van het betrouwbaarheidsinterval van de HR overschreed echter de 1,0 (gecorrigeerde HR 0,86; 95\%-BI 0,72 tot 1,03). Dit resultaat kan derhalve wel als een ondersteunende aanwijzing worden beschouwd, maar niet als sluitend bewijs.

Andere subgroepanalyses op basis van comorbiditeit of eerdere vaccinatie toonden geen duidelijke aanwijzingen voor een effect van vaccinatie op de overall mortaliteit. Patiënten met longziekten zijn kwetsbaarder als zij influenza krijgen, maar ook in deze subgroep konden we geen duidelijk effect aantonen van de eenmalige vaccinatie op de respiratoir gerelateerde seizoensgebonden mortaliteit (gecorrigeerde SHR 0,56; 95\%BI 0,31 tot 1,11 ).

Het lijkt onwaarschijnlijk dat een eventueel langetermijneffect op sterfte volledig toegeschreven kan worden aan één griepvaccinatie bij jongere ouderen in 1991. De trialvaccinatie was echter voor veel deelnemers vermoedelijk de eerste en voor lange tijd enige griepvaccinatie. Griepvaccinatie van 65 -plussers werd pas in 1996 geadviseerd en vaccinatie van 60-plussers pas in 2008. Daarbij komt dat het vaccin uit 1991 overlap toonde met de stammen die in de vijf daaropvolgende jaren circuleerden. Onderzoek suggereert dat influenzavaccinatie het immunologisch geheugen kan triggeren en zo niet alleen bescherming kan bieden tegen verwante griepvirussen, maar ook tegen griepvirussen die in het eropvolgende jaar circuleren., ${ }^{8,11,12}$ Gegeven deze inzichten, de langere mediane overleving van 20,11 maanden bij deelnemers van 60-64 jaar en de effectgrootte in deze subgroep (HR 0,86), kan een beschermend langetermijneffect in deze leeftijdsgroep niet uitgesloten worden.

Methodologisch zijn onze resultaten niet goed vergelijkbaar met de literatuur. Eerdere onderzoeken evalueerden vooral de seizoensgebonden effecten op korte termijn ( 1 jaar), en het onderzoek naar de effecten van vaccinatie op sterfte - al dan niet binnen subgroepen - is in de regel volledig observationeel en dus erg gevoelig voor bias. ${ }^{5,13,14}$ De kortetermijneffecten van griepvaccinatie zijn in diverse systematische reviews bestudeerd: bij thuiswonende ouderen reduceerde vaccinatie de kans op ziekenhuisopname door pneumonie of hartaandoening met ongeveer $25 \%$ (berustend op observationeel onderzoek), en vaccinatie verlaagde de kans op influenza met circa $60 \%$ (berustend op trials). ${ }^{15}$

\section{Sterke punten en beperkingen}

Ons onderzoek heeft een aantal beperkingen. Een daarvan betreft de statistische power. De trial van 1991 was niet ontworpen om een effect op sterfte tijdens datzelfde seizoen te evalueren. Door het hoge percentage deelnemers $(97,9 \%)$ en de lange follow-upduur konden we een groot aantal persoonsjaren en events analyseren. Niettemin toonde een post-hoc poweranalyse aan dat alleen hazardratio's $\leq 0,85$ als significant zouden kunnen worden aangemerkt. Dat wij geen langetermijneffect van griepvaccinatie op sterfte konden aantonen, 
Tabel 3

Effect van vaccinatie op de totale sterfte en op de sterfte door specifieke oorzaken

\begin{tabular}{|c|c|c|c|c|}
\hline \multirow[t]{2}{*}{ Sterfte } & \multirow{2}{*}{$\begin{array}{l}\text { Vaccin] } \\
\text { n [\%] }\end{array}$} & \multirow{2}{*}{$\begin{array}{l}\text { Placebo } \\
\text { n [\%] }\end{array}$} & \multicolumn{2}{|l|}{ [S]HR [95\%-BI] } \\
\hline & & & ongecorrigeerd & gecorrigeerd \\
\hline N & 927 & 911 & & \\
\hline Alle oorzaken & $711[76,7]$ & $707[77,6]$ & $0,94[0,85$ tot 1,05$]$ & $0,95[0,85$ tot 1,05$]$ \\
\hline Respiratoir of circulatoir & $329[35,5]$ & $324[35,6]$ & $0,99[0,85$ tot 1,15$]$ & $0,96[0,82$ tot 1,13$]$ \\
\hline . respiratoir & $80[8,6]$ & $75[8,2]$ & $1,04[0,76$ tot 1,43$]$ & $1,04[0,76$ tot 1,44$]$ \\
\hline circulatoir & $249[26,9]$ & $249[27,3]$ & $0,97[0,81$ tot 1,16$]$ & $0,96[0,80$ tot 1,15$]$ \\
\hline Influenza/pneumonie & $35[3,8]$ & $28[3,1]$ & $1,22[0,74$ tot 2,01$]$ & $1,20[0,73$ tot 1,97$]$ \\
\hline Longziekten [primaire, secundaire of tertiaire oorzaak] & $140[15,1]$ & $134[14,7]$ & $1,02[0,81$ tot 1,29$]$ & $1,07[0,84$ tot 1,37$]$ \\
\hline
\end{tabular}

$\mathrm{HR}$ = hazardratio; SHR = subhazardratio; $\mathrm{BI}$ = betrouwbaarheidsinterval.

Percentages berekend als aantal events gedeeld door aantal patiënten.

zou dus ook kunnen berusten op een type-II-fout als gevolg van een te lage power (waarbij de nulhypothese ten onrechte niet zou zijn verworpen).

In dit onderzoek konden we geen rekening houden met hervaccinaties na 1991, aangezien de bewaartermijn van medische gegevens in veel gevallen al was verstreken. Omdat de verschillen in griepvaccinatiestatus tussen de vaccin- en de placebogroep mettertijd vermoedelijk kleiner zijn geworden, kan dit een eventueel werkelijk bestaand verschil in langetermijnsterfte afgezwakt hebben.

Sterke punten zijn de nagenoeg complete follow-up, op basis van een goed gedocumenteerde RCT, en het feit dat binnen deze trial het vaccin goed gematcht was met de epidemische griepstammen.

Het is de vraag of een nieuw placebogecontroleerd onderzoek door een medisch-ethische toetsingscommissie zou worden goedgekeurd. ${ }^{4,16}$ Met de bestaande kennis over het effect van griepvaccinatie zijn er immers ethische vraagtekens te zetten bij het aan ouderen onthouden van deze standaardzorg.

Daarnaast zou een dergelijke trial aanlopen tegen aanzienlijke methodologische en praktische belemmeringen qua power en uitvoerbaarheid gedurende meerdere griepseizoenen. Mogelijk blijven onze bevindingen daarom voorlopig het enige goed gedocumenteerde bewijsmateriaal over de effecten van griepvaccinatie op de langetermijnsterfte bij thuiswonende ouderen.

\section{CONCLUSIE}

Ons onderzoek kon geen globaal langetermijneffect aantonen van (eenmalige) griepvaccinatie op de sterfte bij thuiswonende ouderen. Rekening houdend met de beperkte power en met de bevindingen in de subgroep jongere ouderen, rechtvaardigen onze resultaten echter nader onderzoek naar het langetermijneffect van griepvaccinatie op de mortaliteit bij ouderen. Onderzoekers die de effectiviteit van griepvaccinatie - en mogelijk ook de meerwaarde van nieuwe vaccins - willen evalueren, doen er goed aan hun onderzoeksopzet geschikt te maken voor een langdurige follow-up.

\section{LITERATUUR}

1. Govaert TM, Thijs CT, Masurel N, Sprenger MJ, Dinant GJ, Knottnerus JA. The efficacy of influenza vaccination in elderly individuals. A randomized double-blind placebo-controlled trial. JAMA 1994;272:1661-5.

2. Beyer WE, McElhaney J, Smith DJ, Monto AS, Nguyen-VanTam JS, Osterhaus AD. Cochrane re-arranged: support for policies to vaccinate elderly people against influenza. Vaccine 2013;31:6030-3.

3. Demicheli V, Jefferson T, Di Pietrantonj C, Ferroni E, Thorning S, Thomas RE, et al. Vaccines for preventing influenza in the elderly. Cochrane Database Syst Rev 2018;2:CD004876.

De volledige literatuurlijst staat bij dit artikel op www.henw.org.

Verhees RA, Thijs C, Ambergen T, Dinant GJ, Knottnerus JA. Griepvaccinatie en langetermijnsterfte. Follow-up 25 jaar na een RCT bij ouderen. Huisarts Wet 2020;63[2]:16-9. D0I:10.1007/s12445-020-0416-0.

Maastricht University, Care and Public Health Research Institute [CAPHRI], Vakgroep Huisartsgeneeskunde, Maastricht: R.A.F. Verhees, huisarts-onderzoeker: ruud.verhees@maastrichtuniversity.nl; prof.dr. G.J. Dinant, huisarts en onderzoeker; prof.dr. J.A. Knottnerus, emeritus hoogleraar Huisartsgeneeskunde. Vakgroep Epidemiologie: dr. C. Thijs, hoofddocent epidemiologie en volksgezondheid. Vakgroep Methodologie en Statistiek: dr. A.W. Ambergen, statisticus. Mogelijke belangenverstrengeling: niets aangegeven. 